uniform. Recently, based on previous clustering analysis and clinical, histopathological, serological and prognostic aspects three subcategories of AAV have been proposed and named as: non-severe AAV, severe PR3-AAV and severe MPO-AAV [1].

Objectives: In line with these attempts to subcategorize AAV we decided to use latent class analysis (LCA) on a large multicenter cohort of polish AAV patients from POLVAS [2] registry to identify potential new subphenotypes or confirm already proposed ones.

Methods: Latent Class Analysis (LCA) approach was used as a model based clustering method of objects described by dichotomous (e.g., gender; ANCA status - cANCA, pANCA; organ involvement - skin, eye, ENT, respiratory, heart, GI, renal, urinary, CNS, peripheral nerves) and polytomous (number of relapses) variables supported by quantitative covariates (e.g., age at diagnosis, CRP at diagnosis, maximal serum creatinine concentration ever).

Results: Results of LCA on our AAV group returned four class model of AAV subphenotypes, confirming existence of the previously proposed by Mahr at al. [1] and revealed fourth - previously not described clinically relevant subphenotype. To this fourth class - belong patients only with GPA, diagnosed at young age, with multiorgan involvement, high relapse rate and relatively high risk of death.

Table 1. AAV subcategorization - summary of clinical characteristics and ANCA specificity

\begin{tabular}{|c|c|c|c|c|}
\hline & LCA Class 1 & LCA Class 2 & LCA Class 3 & LCA Class 4 \\
\hline No of patients & 130 & 194 & 102 & 97 \\
\hline AAV type & Mainly GPA & Mainly GPA & mainly MPA & Only GPA \\
\hline Age at diagnosis & Middle age & Middle age & Old & Young \\
\hline Male/female ratio & $1: 2$ & $2: 1$ & $1: 1$ & $1: 1$ \\
\hline $\begin{array}{l}\text { Main organ } \\
\text { involvement }\end{array}$ & $\begin{array}{l}\text { ENT, respiratory, } \\
\text { eye }\end{array}$ & $\begin{array}{l}\text { Renal, respiratory, } \\
\text { ENT }\end{array}$ & $\begin{array}{l}\text { Renal, respiratory, } \\
\text { skin }\end{array}$ & $\begin{array}{l}\text { Multiorgan } \\
\text { involvement }\end{array}$ \\
\hline Relapse rate & intermediate & intermediate & low & high \\
\hline $\begin{array}{l}\text { Modified class } \\
\text { description } \\
\text { (based on ref. [1]) }\end{array}$ & Non severe AAV & Severe PR3 AAV & Severe MPO AAV & $\begin{array}{l}\text { Severe } \\
\text { non-renal } \\
\text { PR3 AAV }\end{array}$ \\
\hline
\end{tabular}

Conclusion: Based on multiple clinical and serological variables LCA methodology identified 4-class subphenotypes model of AAV. Fourth-class is a new clinically important subphenotype including exclusively PR3-positive young AAV patients with multiorgan involvement, high risk of relapse and distinct mortality. References:

[1] Mahr A, Specks U, Jayne D. Subclassifying ANCA-associated vasculitis: a unifying view of disease spectrum. Rheumatol Oxf Engl 2019;58:1707-9. https://doi.org/10.1093/rheumatology/kez148.

[2] Wójcik K, Wawrzycka-Adamczyk K, Włudarczyk A, Sznajd J, Zdrojewski Z, Masiak A, i in. Clinical characteristics of Polish patients with ANCA-associated vasculitides-retrospective analysis of POLVAS registry. Clinical Rheumatology. 1 wrzesień 2019;38(9):2553-63.

Disclosure of Interests: Krzysztof Wójcik: None declared, Adam Ćmiel: None declared, Anna Masiak: None declared, Zbigniew Zdrojewski: None declared, Radoslaw Jeleniewicz: None declared, Maria Majdan Consultant of: Roche, Amgen, Speakers bureau: Roche, Amgen, Iwona Brzosko: None declared, Marek Brzosko: None declared, Piotr Głuszko: None declared, Małgorzata Stasiek: None declared, Małgorzata Wisłowska: None declared, Joanna KurZalewska: None declared, Marta Madej: None declared, Anna Hawrot-Kawecka: None declared, Hanna Storoniak: None declared, Barbara Bułło-Piontecka: None declared, Alicja Dębska-Ślizień: None declared, Eugeniusz Kucharz: None declared, Katarzyna Jakuszko: None declared, Jacek Musiał: None declared DOI: 10.1136/annrheumdis-2020-eular.832

\section{FRI0224 \\ IDENTIFICATION OF RISK AND PROGNOSTIC FACTORS FOR POLYARTERITIS NODOSA PATIENTS WITH DIGITAL GANGRENE}

D. Xu ${ }^{1}$, X. Tian ${ }^{1}$, X. Zeng ${ }^{1}$, F. Zhang ${ }^{1}$, L. Zhao ${ }^{2}$, S. Zhang ${ }^{1}$, J. Zhou ${ }^{1}$, J. L. Zhao ${ }^{1}$, X. Kong ${ }^{3}$ on behalf of Department of Rheumatology and Clinical Immunology, Peking Union Medical College Hospital, Chinese Academy of Medical Sciences \& Peking Union Medical College, Key Laboratory of Rheumatology and Clinical Immunology, Ministry of Education and Department of Rheumatology, 2nd Affiliated Hospital of Dalian Medical University. ${ }^{1}$ Chinese Academy of Medical Sciences \& Peking Union Medical College, Beijing, China; ${ }^{2} 2 n d$ Affiliated Hospital of Dalian Medical University, Rheumatology, Dalian, China; ${ }^{3} 2 n d$ Affiliated Hospital of Dalian Medical University, Dalian, China

Background: Polyarteritis nodosa (PAN) is a segmental, necrotizing vascular disease that primarily impacts medium-sized muscle arteries. The estimated annual incidence of PAN is still lacking in China. Digital gangrene is an ischemic manifestation of the limb. However, the causes and the treatment methods vary from case to case, and the outcome is unpredictable. These features emphasize the need to identify measurable variables that accelerate digital gangrene development in PAN patients. However, little effort has been made to identify the clinical and laboratory factors that affect PAN patients with digital gangrene to anticipate their natural history and response to therapy.

Objectives: Many patients with polyarteritis nodosa (PAN) complicated with digital gangrene have poor outcomes and related research information is limited. This study was carried out to identify the associated risk and prognostic factors. Methods: We conducted a retrospective study of 148 PAN patients admitted to Peking Union Medical College Hospital (PUMCH) from September 1986 to December 2018. The characteristics, therapeutic regimens, and outcome data for patients with and without gangrene were compared. The Kaplan-Meier method and Cox hazard regression model were used to evaluate the prognostic factors. Results: Forty-seven (31.8\%) PAN patients had digital gangrene complications. The average age was $40.4 \pm 17.9$ years and the average disease duration was 11 (4-27) months. The presence of digital gangrene was correlated with smoking history [odds ratio (OR), 4.27; 95\% confidence interval $(95 \% \mathrm{Cl}), 1.56-11.66$ ] and eosinophil elevation (28.12; 10.30-76.8). Thirty-two (68.1\%) gangrene patients received methylprednisolone pulse therapy and all of these patients were treated with cyclophosphamide. Nine patients suffered irreversible organ injury and two died. Disease duration $\geq 24$ months and elevated serum C-reactive protein (CRP) were identified as hazardous factors for poor prognosis in patients with gangrene $(P=0.003, \mathrm{HR}=8.668,95 \% \mathrm{Cl} 2.11,35.55$ and $P=0.042, \mathrm{HR}=27.062$ $95 \% \mathrm{Cl} 1.13,648.57$, respectively).

Conclusion: Smoking history and eosinophil elevation in PAN patients were more prone to digital gangrene and high serum CRP level predicted poor outcomes. PAN patients with smoking history and elevated eosinophils need to be seriously evaluated by clinicians. Furthermore, the CRP level should be efficiently controlled for good prognosis.

References:

[1] De Virgilio A, Greco A, Magliulo G, Gallo A, Ruoppolo G, Conte M, et al. Polyarteritis nodosa: A contemporary overview. Autoimmun Rev. 2016;15:564-70.

[2] Pagnoux C, Seror R, Henegar C, Mahr A, Cohen P, Le Guern V, et al. Clinica features and outcomes in 348 patients with polyarteritis nodosa: a systematic retrospective study of patients diagnosed between 1963 and 2005 and entered into the French Vasculitis Study Group Database. Arthritis Rheum. 2010;62:616-26.

[3] Xu D, You X, Wang Z, Zeng Q, Xu J, Jiang L, et al. Chinese Systemic Lupus Erythematosus Treatment and Research Group Registry VI: Effect of Cigarette Smoking on the Clinical Phenotype of Chinese Patients with Systemic Lupus Erythematosus. PLoS One. 2015;10:e0134451.

Acknowledgments: No

Disclosure of Interests: Dong Xu: None declared, Xinping Tian: None declared Xiaofeng Zeng Consultant of: MSD Pharmaceuticals, Fengchun Zhang: None declared, Lin Zhao: None declared, Shangzhu Zhang: None declared, Jiaxin Zhou: None declared, Jiu-liang Zhao: None declared, Xiaodan Kong: None declared

DOI: 10.1136/annrheumdis-2020-eular.817

\section{FRI0225 CAVA INVOLVEMENT IN BEHCET'S DISEASE}

J. Zhou ${ }^{1}$, J. Liu ${ }^{1}$, Y. Wang ${ }^{2}$, W. Zheng ${ }^{1} .{ }^{1}$ Peking Union Medical College Hospital, Rheumatology, Beijing, China; ${ }^{2}$ Peking Union Medical College Hospital, Radiology, Beijing, China

Background: Behcet's disease (BD) is a systemic disease that can affect ves sels of any size and type. However, only limited cases of BD patients with vena cava involvement have been reported.

Objectives: To investigate the clinical features and outcome of vena cava involvement in BD patients.

Methods: We retrospectively reviewed the clinical data of BD patients with vena cava involvement in our institute from August 2001 to October 2019. The treatment and outcome of these patients were also analyzed.

Results: Fifty BD patients with vena cava involvement were included. The median interval between $\mathrm{BD}$ onset and diagnosis of vena cava involvement was 2.8 (range $0-19.4)$ years. Superior vena cava (SVC) involvement was detected in $22(44.0 \%)$ patients, and 21 patients had typical manifestations of SVC syndrome. Inferior vena cava (IVC) was detected in 35 (70.0\%) patients, including 7 patients diagnosed with Budd-Chiari syndrome. Seven patients had both superior and inferior vena cava involvement. Forty-five $(90.0 \%)$ patients had venous involvement other than vena cava, including 19 patients with common iliac thrombosis, 12 patients with common femoral vein thrombosis, 11 patients with external iliac vein thrombosis, etc. For the other BD manifestations, oral ulceration was presented in all patients followed by genital ulceration (35, 70.0\%), Erythema nodosum $(27,54.0 \%)$ and pathergy reaction $(25,50.0 \%)$. Thirteen $(26 \%)$ patients had eye involvement. Ten (20\%) patients had pleural and/or pericardial effusions. Eleven $(22.0 \%)$ patients had pulmonary thromboembolism, and $4(8.0 \%)$ patients had arterial involvement. 
Inflammatory markers were significantly elevated in 41 (82.0\%) patients when the vena cava involvement developed, the mean ESR was $34.0 \pm 29.2 \mathrm{~mm} / \mathrm{hr}$, and the median CRP level was 19.9(0.2-177.0) $\mathrm{mg} / \mathrm{L}$. The mean BDCAF2006 score of all patients was $4.6 \pm 1.6$. Glucocorticoid was used in 47 (94.0\%) patients after vena cava involvement was diagnosed, and cyclophosphamide was the first-choice immunosuppressant. Forty-one (82.0\%) patients received anticoagulation treatment. Five patients had received placement of IVC filter, and 3 patients had taken balloon dilation of IVC. With a mean follow up of $4.1 \pm 3.8$ years, 45 patients $(90.0 \%)$ achieved clinical improvements, 6 patients $(12.0 \%)$ had relapse of vascular involvement, 5 patients (10.0\%) died. The respective estimated cumulative 1- and 5 - years relapse-free rates were $90.9 \%$ and $83.1 \%$, and the respective estimated 1 - and 5 - years survival rates were $95.9 \%$ and $90.1 \%$.

Conclusion: Vena cava involvement is a rare complication in BD patients. The prognosis of these patients is relatively optimistic after proper treatment. To the best of our knowledge, our study is the largest cohort of BD patients with vena cava involvement.

\section{References:}

[1] Y. Fei, X. Li, S. Lin et al. Major vascular involvement in Behçet's disease: a retrospective study of 796 patients. Clinical Rheumatology, 2013, 32 (6): 845-852.

[2] Seyahi E, Caglar E, Ugurlu S et al. An outcome survey of 43 patients with Budd-Chiari syndrome due to Behçet's syndrome followed up at a single, dedicated center. Semin Arthritis Rheum, 2015, 44(5):602-609.

Acknowledgments: We gratefully thank all the patients who participated in our study.

Disclosure of Interests: None declared

DOI: 10.1136/annrheumdis-2020-eular.4507

FRIDAY, 05 JUNE 2020

\section{Scleroderma, myositis and related syndromes}

\section{FRI0226 \\ OPTICAL COHERENCE TOMOGRAPHY OF THE SKIN DETECTS SCLERODERMA CHANGES IN CLINICALLY UNAFFECTED SKIN: AN OPPORTUNITY FOR EARLY DETECTION OF SYSTEMIC SCLEROSIS}

G. Abignano $^{1,2}$, D. Temiz Karadağ $\breve{~}^{1,3}$, O. Gundogdu ${ }^{4}$, G. Lettieri ${ }^{5}$, M. C. Padula ${ }^{1}$, A. Padula ${ }^{1}$, P. Emery ${ }^{2}$, S. D'angelo ${ }^{1}$, F. Del Galdo ${ }^{2} .{ }^{1}$ Rheumatology Institute of Lucania (IReL), Rheumatology Department of Lucania, San Carlo Hospital, Potenza, Italy; ${ }^{2}$ Leeds Institute of Rheumatic and Musculoskeletal Medicine, University of Leeds, Leeds, United Kingdom; ${ }^{3}$ Canakkale State Hospital, Rheumatology Clinic, Canakkale, Turkey; ${ }^{4}$ Department of Biomedical Engineering, Kocaeli University, Kocaeli, Turkey; ${ }^{5}$ Radiology Department, San Carlo Hospital, Potenza, Italy

Background: The Very Early Diagnosis Of Systemic Sclerosis (VEDOSS) study has shown that $82 \%$ of patients with Raynaud's Phenomenon, specific ANA positivity and scleroderma pattern at nail fold videocapillaroscopy will fulfil classification criteria within 5 years. This is suggesting that there is a subclinical window of opportunity to diagnose systemic sclerosis (SSc) before clinical manifestations occur. In this scenario, a non-invasive tool to diagnose SSc in clinically unaffected skin might improve the early detection of disease in at risk-patients. Optical coherence tomography (OCT) of the skin has been shown to be a sensitive and accurate biomarker of skin fibrosis in SSc.

Objectives: Here we aimed to assess the ability of skin OCT to "detect" SSc in clinically unaffected skin from a multicentre cohort.

Methods: Dorsal forearm skin of SSc patients and matched-healthy controls (HC) was evaluated using VivoSight scanner (Michelson Diagnostics). Mean A-scans (mean OCT signal plotted against depth-in-tissue) were derived as previously described. Minimum Optical Density (MinOD), Maximum OD (MaxOD) and OD at 300 micron-depth (OD300) were calculated. Clinical involvement was assessed by an operator blinded to OCT findings using the mRSS. Receiver-operating characteristic (ROC) curve analysis was carried out for MinOD, MaxOD, and OD300 to evaluate their ability to discriminate between SSc and HC. Statistical analysis was performed using GraphPad Prism software V.7.0.

Results: One hundred seventy four OCT images were collected from 87 subjects [43 SSc (39 Female, mean age 49.7 \pm 9.1 years) and 44 gender/ age-matched healthy controls ( $\mathrm{HC}$ ) (36 Female, mean age 50.2 \pm 8.3 years)] in two different SSc centres. All patients fulfilled classification criteria for SSc. OCT measures demonstrated discriminative ability in SSc skin detection with any clinical skin involvement (0-3 at site of analysis) with an AUC of 0.73 (MinOD, 95\% Cl 0.64-0.81), 0.77 (MaxOD, 95\% $\mathrm{Cl} 0.7-0.85$ ) and 0.82 (OD300, 95\% Cl 0.76-0.89); $\mathrm{p}<0.0001$ for all as previously indicated. Most importantly, all three measures showed comparable performance in detecting scleroderma also in clinically unaffected skin (mRss $=0$ at site of analysis), with an AUC of 0.7 (95\% Cl 0.6-0.81, p=0.001), $0.72(95 \% \mathrm{Cl} 0.61$ $0.83, \mathrm{p}=0.0003)$ and $0.72(95 \% \mathrm{Cl} 0.61-0.83, \mathrm{p}=0.0003)$ for MinOD, MaxOD and OD300 respectively.

Conclusion: Virtual biopsy by OCT recognises clinically unaffected skin of SSc patients from the HC skin. This is consistent with gene array data showing that scleroderma specific signatures are consistent in affected and clinically unaffected skin. These results inform future studies on at risk patients with clinically unaffected skin which may define a role for OCT in detecting subclinical SSc.

Disclosure of Interests: Giuseppina Abignano: None declared, Duygu Temiz Karadağ: None declared, Ozcan Gundogdu: None declared, Giovanni Lettieri: None declared, Maria Carmela Padula: None declared, Angela Padula: None declared, Paul Emery Grant/research support from: AbbVie, Bristol-Myers Squibb, Merck Sharp \& Dohme, Pfizer, Roche (all paid to employer), Consultan of: AbbVie (consultant, clinical trials, advisor), Bristol-Myers Squibb (consultant, clinical trials, advisor), Lilly (clinical trials, advisor), Merck Sharp \& Dohme (consultant, clinical trials, advisor), Novartis (consultant, clinical trials, advisor), Pfizer (consultant, clinical trials, advisor), Roche (consultant, clinical trials, advisor), Samsung (clinical trials, advisor), Sandoz (clinical trials, advisor), UCB (consultant, clinical trials, advisor), Salvatore D’Angelo: None declared, Francesco Del Galdo: None declared DOI: 10.1136/annrheumdis-2020-eular.6589

\begin{tabular}{|l|l}
\hline FRI0227 & A USABILITY SURVEY OF WRIST MOUNTED \\
DISPOSABLE HEAT PAD ON RAYNAUD'S \\
PHENOMENON IN PATIENTS WITH CONNECTIVE \\
TISSUE DISEASES
\end{tabular}

N. Azuma ${ }^{1}$, T. Furukawa ${ }^{1}$, Y. Shima ${ }^{2}$, K. Matsui ${ }^{1}{ }^{1}$ Hyogo College of Medicine, Division of Diabetes, Endocrinology and Clinical Immunology, Nishinomiya, Japan; ${ }^{2}$ Osaka University Graduate School of Medicine, Department of Thermo-therapeutics for Vascular Dysfunction, Suita, Japan

Background: For patients with connective tissue diseases (CTD), vasodilators are used to treat Raynaud's phenomenon (RP), they are difficult to control only by medication. Although physicians recommend the use of a portable handwarmer or gloves to patients with CTD presenting with RP, sustained heat-retention effects cannot be obtained from them because the patients' daily life-related activities prevent their continued use. Since the wrist mounted disposable heat pad maintains the degrees of freedom of the hands and fingers and can remain usable during the daily activities, we considered this heat pad as a useful and highly practical heating method for CTD patients presenting with RP.

Objectives: To investigate the usability and changes in symptoms resulting from the use of the wrist mounted disposable heat pad in CTD patients presenting with RP. Methods: Subjects were 23 outpatients with CTD presenting with RP (23 females; mean age 62.6 years; mean duration following the onset of RP 10.3 years; 12 systemic sclerosis, 5 mixed connective tissue disease, 5 Sjögren's syndrome, and 1 systemic lupus erythematosus) who had used the wrist mounted disposable heat pad (put the pad in a specifically designed holder and wrap it around wrist joint (max. temperature 42 degrees Celsius, heat-retention time 6 hours)). We investigated through interviews with them the use situations, usability, and changes in RP. During their using the heat pad, medication and daily life-related precautions against RP continued to be implemented as before.

Results: Many patients had no knowledge of the heat pad $(n=17,73.9 \%)$. The most common wearing time of the heat pad was $5-6$ hours $(n=8,34.8 \%)$. As for scenes of wearing the heat pad, patients who wore the pad when being out of the home accounted for the highest proportion $(n=16,69.6 \%)$, and as follows: at home $(n=6,26.1 \%)$, during kitchen work $(n=3,13.0 \%)$, and during housework $(n=2,8.7 \%) .17$ patients $(73.9 \%)$ replied that usability was "good", and $18(78.3 \%)$ replied that usability was "better" compared with conventional measures. Moreover, many patients $(n=16,69.6 \%)$ replied that RP and associated symptoms had become reduced or alleviated. No patients replied that RP and associated symptoms had become exacerbated or severer. In terms of advantages of using the heat pad, patients who replied that the site on which the pad was mounted was felt to be warm accounted for the highest proportion $(n=8,34.8 \%)$, and those who replied that sites other than where the pad was mounted (such as fingertips, hands, and arms) were also warmed accounted for virtually the same proportion $(n=7,30.4 \%)$. Over $60 \%$ of the patients $(n=14$, $60.9 \%$ ) replied that symptoms associated with RP (skin color, cold sensation, and pain) had become reduced or disappeared. In terms of disadvantages of using the heat pad, patients who replied that it was bothersome to use the pad accounted for the highest proportion while other patients made replies referring to cost and bad appearance. No significant accident occurred and as many as 17 patients (73.9\%) replied that they would like to continue to use the heat pad in the future. 